\title{
Fetal Thanatophoric Dysplasia
}

\author{
Samsudeen $\mathrm{MF}^{\mathrm{a}}$, Maggonage $\mathrm{CG}^{\mathrm{b}}$, Wedisha $\mathrm{IG}^{\mathrm{c}}$, Thuvaratheepan $\mathbf{R}^{\mathrm{d}}$, Kaluarachchi $\mathrm{A}^{\mathrm{e}}$
}

\begin{abstract}
Thanatophoric dysplasia (TD) is a rare autosomal dominant lethal skeletal dysplasia with two subtypes. Mutations in the fibroblast growth factor receptor 3 gene (FGFR3) results in both subtypes. In prenatal diagnosis of TD by three-dimensional ultrasound examination in second trimester aids in visualizing facial features and other soft tissue findings such as cloverleaf skull, very short extremities and small thorax. Most of the affected fetuses die in utero or shortly after birth due to either respiratory insufficiency or brain stem compression or combination of both. We report one such rare case of type I TD encountered at 32 weeks of gestational age.
\end{abstract}

Key Words: Thanatophoric dysplasia, skeletal dysplasia.

\section{INTRODUCTION}

TD is the most common form of skeletal dysplasia which is lethal in the neonatal period and it has an incidence of 1 per 20,000 to 1 per 50,000 births $^{1}$. There are Type I and Type II subtypes with relative incidence of $80 \%$ and $20 \%$ respectively. Autosomal dominant mutations in the fibroblast growth factor receptor 3 gene (FGFR3), which has been mapped to chromosome band $4 \mathrm{p} 16.3$, results in both subtypes ${ }^{2}$.

\section{CASE REPORT}

A 28 year old woman in her $1^{\text {st }}$ pregnancy with an uncomplicated preconception

\footnotetext{
${ }^{a}$ Registrar in obstetrics \& Gynaecology,

${ }^{b}$ Senior Registrar in obstetrics \& Gynaecology,

${ }^{c}$ Registrar in obstetrics \& Gynaecology,

${ }^{d}$ Registrar in obstetrics \& Gynaecology,

e Professor in Obstetrics \& Gynaecology, Professorial Unit, De Soysa Hospital for Women, Colombo, Sri Lanka

Correspondence: Dr. S M Fahim MBBS

Email:smfahimm05@yahoo.com

(D) https://orcid.org/0000-0002-4503-6352

Competing interests: The authors report no conflict of interest
}

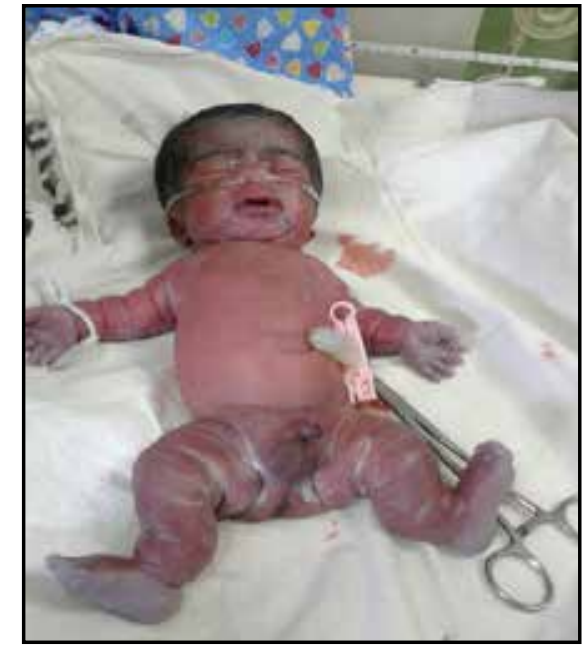

and antenatal period found to be carrying a fetus with thanatophoric skeletal dysplasia by routine anomaly ultrasound scan at 22 weeks of gestation with features of macrocephaly, narrow chest, deformed shorten limbs, scoliosis and polyhydramnios. As no legal provisions are available for termination of pregnancy for lethal congenital anomalies, both parents were counselled and decided to continue the pregnancy. At 32 weeks of gestation she was admitted to the hospital with preterm labour and assisted breech vaginal delivery was performed. Mother had uneventful recovery.

Baby boy weighed $1.75 \mathrm{~kg}$ developed peripheral cyanosis and respiratory distress immediately after delivery, admitted to neonatal intensive care unit and expired on the same day due to respiratory failure. Baby had macrocephaly with head circumference of $320 \mathrm{~mm}$ (above $90^{\text {th }}$ centile). Anterior and posterior fontanelle were widely open and sutures were separated. The head and neck features were prominent forehead, mid facial hypoplasia, depressed nasal bridge, low set ears and short neck. Upper and lower limbs were short with short stubby fingers and extra deep skin folds. Narrow

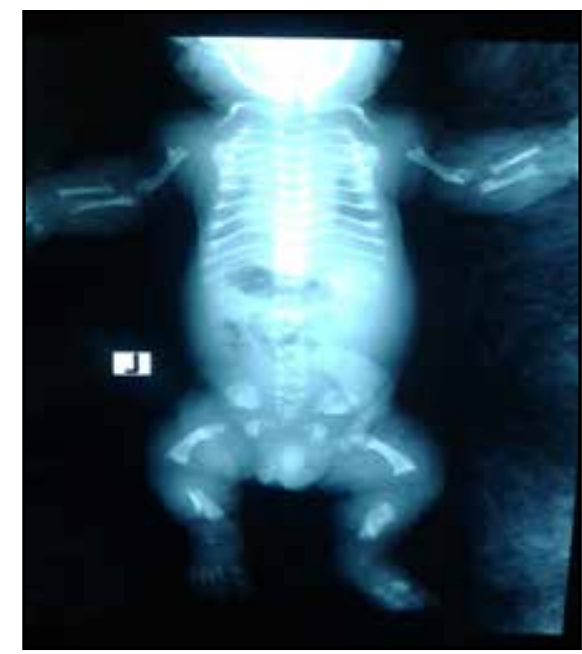

thorax, protuberant abdomen and scoliotic spine were also seen.

Full body x-ray reveled narrow chest with small ribs and short long bones [humerus $-25 \mathrm{~mm}\left(<3^{\text {rd }}\right.$ centile $)$, femur $-28 \mathrm{~mm}(<$ $3^{\text {rd }}$ centile)] with the shape of telephone receiver. With facial features and skeletal abnormalities the diagnosis of TD type I was made. Post mortem confirmed the diagnosis and no placental abnormalities detected. Both parents were debriefed and counselled.

\section{DISCUSSION}

TD is a congenital, sporadic, usually lethal skeletal dysplasia with two clinically defined subtypes, type I and Type II with 
some overlap between the two subtypes. Differential diagnosis of TD includes homozygous achondroplasia, severe hypophosphatasia, severe osteogenesis imperfecta, achondrogenesis, campomelic dwarfism and rhizomelic chondrodysplasia punctata $^{3}$. Thanatophoric dysplasia or dwarfism literally meaning death bearing dwarf was first described by Maroteaux et al. ${ }^{4}$. It is caused by autosomal dominant mutations in the fibroblast growth factor receptor 3 (FGFR3) gene, which has been mapped to chromosome band 4p16.3. This gene provides instructions for making a protein that is involved in the development and maintenance of bone and brain tissue. Mutations in this gene cause the FGFR3 protein to be overly active, which leads to the severe disturbance in bone growth that is characteristic of $\mathrm{TD}^{2}$. The two subtypes can be differentiated by the skull shape and femur morphology ${ }^{5}$. Type 1 presenting with polyhydramnios, macrocephaly, short limbs, narrow thoracic cage and curved short femur (typical telephone receiver appearance) but without a cloverleaf skull which means a tri-lobed skull. Type 2 is characterized by short limbs, narrow thoracic cage, straight short femora, hydrocephalus, and cloverleaf skull ${ }^{6}$.

In prenatal diagnosis of TD by threedimensional ultrasound examination in second trimester aids in visualizing facial features and other soft tissue findings such as cloverleaf skull, very short extremities and small thorax? ${ }^{7}$. It can be confirmed by molecular analysis of the mutation in FGFR3 gene extracted from fetal cells obtained by amniocentesis usually performed at 15-18 weeks gestation or chorionic villous sampling at about 10 12 weeks gestation ${ }^{8}$. Parental genetic screening for FGFR3 is not useful as almost all cases of TD are caused by new mutation in the FGFR3 gene and occur in people with no history of the disorder in their family. Affected individuals never survive. Therefore, disorder never passes to next generation ${ }^{9}$. Recurrence risk is also not increased above that of the general population as it is a de novo mutation ${ }^{10}$.

Postmortem histology of long bones of the affected fetus shows disorganized chondrocytes columns, poor cellular proliferation, lateral overgrowth of metaphyses, and increased vascularity of cartilage ${ }^{1}$.

Most of the affected fetuses die in utero or shortly after birth. The cause of death is due to either respiratory insufficiency due to narrow chest cavity and hypoplastic lungs or brain stem compression by the narrow foramen magnum or combination of both. Surviving neonate is almost always ventilator dependent and mentally deficient ${ }^{9}$.

\section{REFERENCES}

1. Wilcox WR, Tavormina PL, Krakow D, Lachman RS, Wasmuth JJ, Thompson LM, et al. Molecular radiologic and histopathologic correlations in thanatophoric dysplasia. Am J Med Genet. 1998;78: 274-81.

2. Van Ravenswaaij-Arts CM, Losekoot M. From gene to disease; Achondroplasia and other skeletal dysplasias due to an activating mutation in the fibroblast growth factor. Ned Tijdschr Geneeskd. 2001; 145 (22): 1056-59.

3. Gorlin RJ, Cohen MM, Hennekam RCM, eds. Syndromes of the Head and Neck. 4th ed. New York: Oxford University Press, 2001; 481.
4. Maroteaux P, Lamy M, Robert JM. Thanatophoric dwarfism. Presse Med.1967;75: 2519-24.

5. Tirumalasetti N. Case report of Thanatophoric dysplasia: A lethal skeletal dysplasia. JNTR Univ Health Sci. 2013; 2: 275-77.

6. Chen CP, Chern SR, Stuh JC, Wang W, Yeh LF, Chang TY, Tzen CY. Prenatal diagnosis and genetic analysis of type 1 and 2 Thanatophoric dysplasia. Prenat Diag 2001; 21: 89-95.

7. Phatak SV, Pandit MP, Phatak MS, Kashikar R. Antenatal sonography diagnosis of Thanatophoric dysplasia: A case report. Indian Journal of Radiology and Imaging. 2004; 14(2): 161-63.

8. Rousseau F, el Ghouzzi V, Delezoide AL, Legai-Mallet L, Le Merrer M, Munnich A, et al. FGFR3 mutations create cysteine residues in Thanatophoric dwarfism type I. Hum Mol Genet. 1996; 5: 509-12.

9. Naveen NS, Murlimanju BV, Kumar V, Pulakunta T, Jeeyar H. Thanatophoric Dysplasia: A Rare Entity. Oman Medical Journal. 2011; 26(3): 196-97.

10. Kocherla K, Kocherla V. Antenatal diagnosis of Thanatophoric Dysplasia: a case report and review of literature. Int J Res Med Sci. 2014; 2(3): 1176-79. 